\title{
DOUBLE CHAMBER LEFT VENTRICLE ASSOCIATED WITH SEVERE FORM OF HYPERTROPHIC CARDIOMYOPATHY
}

\author{
Ramush BEJIQI ${ }^{1}$, Ragip RETKOCERI ${ }^{1}$, Hana BEJIQI ${ }^{2}$
}

${ }^{1}$ Division of Cardiology, Pediatric Clinic

University Clinical Center of Kosovo

Prishtina, Republic of Kosovo

${ }^{2}$ Main Center of Family Medicine

Prishtina, Republic of Kosovo

In a 28-month-old girl, from a normal pregnancy and absolutely healthy parents, weighing $16.3 \mathrm{~kg}$, a systolic murmur was noted during a routine pediatric examination and she was referred for cardiological examination at tertiary level. The child's growth and development were completely normal. Her arterial blood gas level was within normal limits. The clinical examination demonstrated: a quiet precordium, normal first heart sound, short midsystolic murmur 2-3/6 degree on the apex and left sternal border, and a single second heart sound. The electrocardiogram showed: left axis deviation, and biventricular hypertrophy. A chest radiogram revealed an enlarged cardiac silhouette with a narrow mediastinum. Echocardiography demonstrated: normal systemic and pulmonary vein connections, with reduced interatrial communication. There were normal atrio-ventricular and ventriculo-arterial connections. From an apical four-chamber view, symmetric hypertrophy of the left ventricle was demonstrated during diastole, and a subaortic obstruction, together with interventricular septal hypertrophy and thickening. In addition, the echocardiographic examination revealed 2
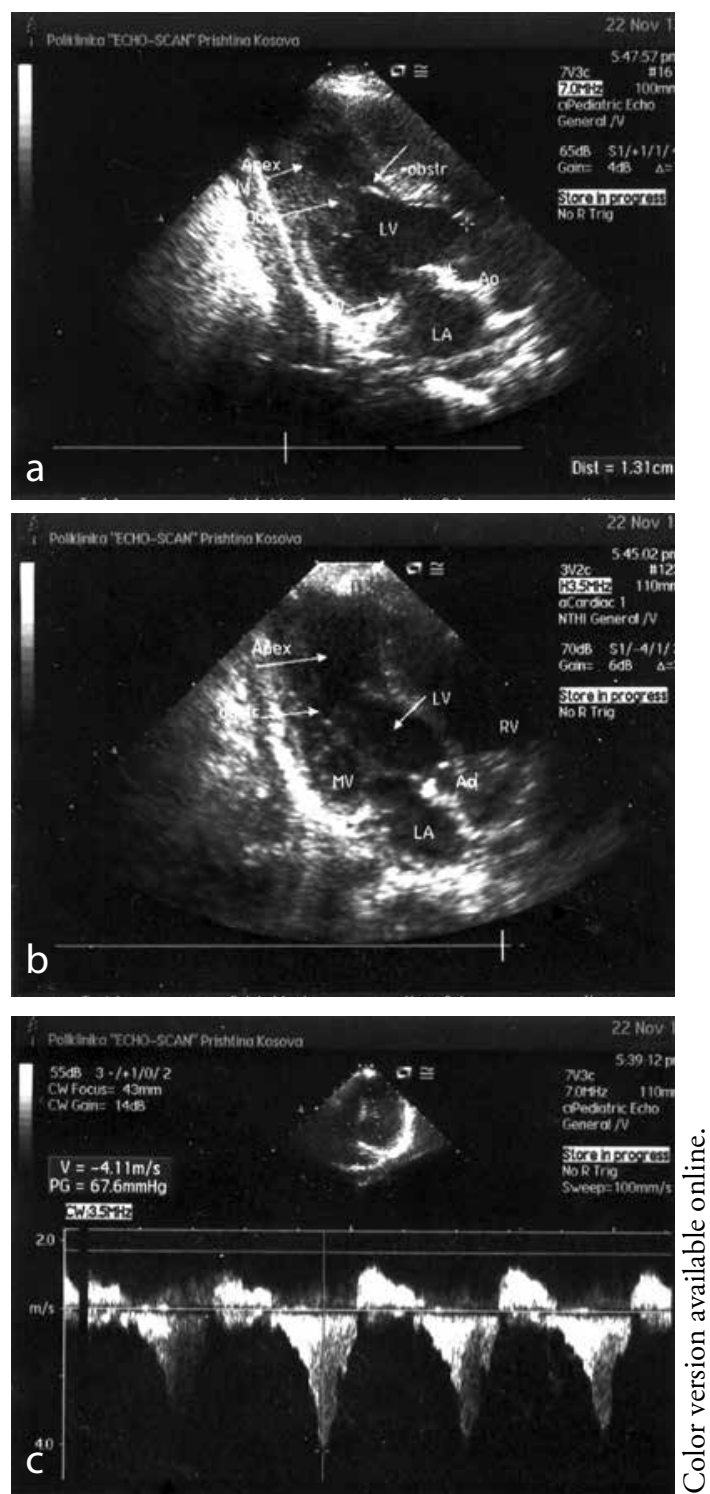
chambers divided by a muscular hypertrophic mass. The hypertrophy was symmetric and severe, causing the cavity of the left ventricle to be anatomically divided into two separate parts. The apical part was seen to be separated from the outlet and inlet portion, but was clearly presented and was actively taking part in left ventricle contractility (Panel A, Panel B). On continuous Doppler waves minor mitral regurgitation was noted. A systolic gradient between the two left chambers was measured with maximum velocity of $4.1 \mathrm{~m} / \mathrm{s}$ and a gradient of $67 \mathrm{~mm}$ of mercury (Panel C). Color Doppler showed a narrow and turbulent color area in systole on the middle part of the left ventricle, running to the mitral valve. This raised doubts that this was more likely a case of double chamber left ventricle associated with HCM than a case with diverticulum or aneurysm of the left ventricle.
Key words: Double chamber left ventricle - Family screening - Hypertrophic cardiomyopathy - Echocardiography.

Authors' contributions: Conception and design: RB, RR; Acquisition, analysis and interpretation of data: $\mathrm{HB}, \mathrm{NZ}$; Drafting the manuscript: RB, RR; Revising it critically for important intellectual content: MB, AM.

Conflict of interest: The authors declare that they have no conflict of interest.

Corresponding author:

Ramush Bejiqi

Division of Cardiology

Pediatric Clinic

University Clinical Center of Kosovo

Prishtina, Republic of Kosovo

rbejiqi@hotmail.com

Tel.: + 37744120 129; Fax.: + 38138553217

Received: January 21, 2013; Accepted: April 2, 2013

Copyright (C) 2013 by University Clinical Center

Tuzla. E-mail for permission to publish:

paediatricstoday@ukctuzla.ba 